\title{
Ergonomic Risk Factors in Ground Handling Operations to Improve Corporate Performance
}

\author{
Vildan Durmaz ${ }^{1}$ Ebru Yazgan²*, Ayse Kucuk Y1lmaz ${ }^{3}$ \\ ${ }^{1}$ Eskisehir Technical University Faculty of Aeronautics and Astronautics, Department of Aviation Management, \\ Eskisehir, Turkey \\ vkorul@eskisehir.edu.tr - (D) 0000-0003-3649-1780 \\ ${ }^{2}$ Eskisehir Technical University Faculty of Aeronautics and Astronautics, Department of Airframe and Power plant \\ Maintenance, Eskisehir, Turkey, \\ eyazgan@eskisehir.edu.tr- (D) 0000-0002-6545-8536 \\ ${ }^{3}$ Eskisehir Technical University Faculty of Aeronautics and Astronautics, Department of Aviation Management, \\ Eskisehir, Turkey, \\ akucukyilmaz@eskisehir.edu.tr- (D) 0000-0001-5240-1023
}

Keywords

\author{
Ergonomic risk \\ Human factors \\ Ground handling \\ Operations \\ Corporate performance
}

Time Scale of Article

Received 12 September 2021 Revised until 7 November 2021 Accepted 24 November 2021 Online date 24 December 2021

\section{Introduction}

The aviation industry defines hazard identification and safety risk management as core processes involved in the management of safety. The concept of safety in aviation may have different connotations, like freedom from hazards or no accident. So, it is essential to understand and identify the factors that cause or are likely to cause harm (Čokorilo and Dell'Acqua, 2013).

Ideas on the impact of the human factor in aviation have inspired the scientific world. Many types of research are carried out and developed models to explain the existence of a relationship between the human factor and the risk of a health or life-threatening event. The risk associated with the presence of the human factor is particularly striking in aviation. There are some uncertainties in aviation operations which make up the risk definition. Those uncertainties are associated with the threat of losing some of the values like life, health, material goods. Otherwise, the perception of risk is influenced by personality factors and situational factors (Uchroński, 2020).

Ground handling operations are one of the most important work performances in the civil aviation flight cycle. Ground handling refers to the wide variety of activities for the flight operations, such as passenger services, flight operations, catering, and baggage handling (EC, 2021). In handling aircraft while refueling, cleaning, loading/unloading, towing, and so forth,

*: Corresponding Author Ebru Yazgan, eyazgan@eskisehir.edu.tr

DOI: $10.23890 /$ IJAST.vm02is02.0205 
effective and safe performance needs to be achieved. The ramp area is also risky both for personnel and operations. Improper use of ground handling equipment, careless and untrained staff may increase safety concerns (Ek and Akselsson, 2007).

As the aviation industry has grown rapidly, supportive handling operational activities need to be grown as well. An increase in traffic means the number of accidents and adverse impacts may rise even in the safest system (Luxhøj et al. 2001). For the efficiency and sustainability of airlines, airport apron area operations are significant. The operation time in this area is short, and at the same time, several activities with different equipment have to be implemented. For that reason, there is a high potential risk for accidents and incidents (Sari et al., 2015). The methodology in this study was determined as taxonomy. Taxonomy is a process approach to deal with risks as to the initial step of the whole management system. In this view, we have tried to embody all related ergonomic factors in a taxonomy. Taxonomy has been designed under four main groups in the view of sustainability management for identified fields that may have an impact. This taxonomy may consider a holistic picture of organization-wide risk factors by managers to reach corporate performance. In this taxonomy for aircraft ground operations, we have identified 13 risks obtained from literature and experts' opinions in the aviation sector.

Corporate performance is a compound evaluation of an organization in, typically, financial, market and shareholder performance parameters. Corporate performance analysis is concerned with the health of the organization. Traditionally, financial performance was significant. Today, the concept has become broader and corporate performance management (CPM) focuses not only on forecasting, budgeting and planning and performance results but also in non-financial areas monitored for corporate performance management and reporting, including strategic planning, process efficiencies, brand equity, risk management and human resource management (HRM) (Wigmore, 2015). Guest et al. (2003) explore the relationship between the use of human resource management and a range of performance measures in manufacturing and service organizations. Kansoy and Bakanoğlu (2021) stated that aviation-related intense workload, staff performance stress may cause accidents and incidents as well as the impact of the nature of human. Bastola (2017) developed a rewarding universal performance model for corporate aviation performance focusing on the employee, teamwork, leadership so on.

Human makes mistakes naturally, so the variable qualities of human resources create difficulties in managing their corporate performance. This is exactly why the sources of error must be identified and managed in a way that does not cause errors. The physical and mental workload affects the health and performance of the ground operations personnel. The level of total workload is significantly affected by environmental and organizational factors as well as mental and physical factors (Emeç and Akkaya,2018; Can and Delice, 2020). If individual performance increases and is used for achieving corporate aims, corporate performance will also increase in view of ground handling services.

Ground handling operations also enable the formation and development of collaborations with aviation sector stakeholders. Managers also will be able to see to which areas they will allocate resources with this taxonomy. This taxonomy may contribute to proactive monitoring of the risk sources about human factors. The proactive approach is important to saving sources. Also, this proactive approach will be useful in reducing the negative effects of risks arising from risk sources before accidents and breakdowns occur.

This new taxonomy, designed as a decision-making tool, may be used as a guide to managing risk for improving both operational and corporate performance. Then managers can also use this taxonomy to manage risks in ground operations. This tool may support in achieving their managerial decision skills for developing human resource qualifications, scheduling workload, mental and physical conditions.

To improve corporate performance on ground operations, many efforts are needed to assure safe operational conditions preventing from hurting the personnel (Sari, 2015). Identifying the ergonomic risk factors aims to evaluate the risks and try to control those activities in the phase of aircraft preparation and turnaround at the ramp area.

Ground handling operations employees are the first to intervene on the aircraft. They are placed at the first and last observation points for flight safety. Therefore, they must have the proper reflexes, the necessary training, correct reactions, and attitude. It is not easy to be a wellequipped staff member in every aspect. Some of these features are acquired through education, some through experience, and some through communication and awareness-raising or as a result of handling incidents (Dupin et al., 2015).

Ergonomics is all about the component of human factors, which are related to the physical body and related tasks with equipment design. To reduce the number of incidents, it is better to establish an ergonomics program (FAA, 2007). Paying attention to ergonomics makes the management issues meaningful. In this way, work requires less effort, and it takes less time while the work gets more productive. On the other hand, ignoring ergonomics is costly- losing time to the loss of livelihood in the most severe injuries. In order to 
find a solution to those issues, it is better to redesign the work practices by making the work easier (Seeley, 2009).

Yazgan (2018), in her study, suggested a holistic framework for working environment systems for technicians by developing human risk taxonomy within ergonomics and corporate performance in aviation.

The results of this study may be adapted to other departments of ground handling, so the company can seize the opportunity to identify all risk sources to deal with them before the accident and/or incidents in the airport. The taxonomy developed in this study may contribute to current literature besides supporting the decision-making process of managers while managing human error especially caused by ergonomic factors in ground handling operations.

\section{Ergonomic Risk and Risk Assessment}

Ergonomics is defined by International Ergonomics Association as "...the scientific discipline concerned with the understanding of interactions among humans and other elements of a system, and the profession that applies theory, principles, data and methods to design in order to optimize human well-being and overall system performance" (Middlesworth, 2018).

The goals of ergonomic interventions should be determined and explained all over the organization. Although it varies according to the structure of the organizations, the most basic targets are given below (FAA ATA Specification 113- Chapter 7):

- Reduce error

- Few injuries/ illness

- Few health issues

- Productivity

- Better quality

There are some studies in aviation focusing on ergonomics of lifting by the baggage handlers who have workplace injuries on the ramp as Asadi, Mott, and $\mathrm{Yu}$ (2019) found that ramp personnel has higher workload and musculoskeletal injury risks. Bern et al. discussed the relationship between heavy lifting in awkward positions and the risk of pain. They observed 3092 baggage handlers. The study showed that the baggage handlers highly self-reported musculoskeletal symptoms during the last 12 months in the neck, shoulders, elbows, wrists, hips, and knees compared to the non-baggage handlers (Asadi, Mott, and Yu, 2019).

As the importance of human resources in management develops, its reflections on aviation applications have been noticed recently. The relationship between man, machine, and the number and cause of mistakes made it the centre of attention of researchers. The concepts of the human factor and ergonomic have close connections. The word "ergonomic" is preferred by European countries, Australia, and New Zealand, and the term "human factor" is used by Americans (Uchroński, 2020).

In the aviation industry, in the "man-machineenvironment" ergonomic model, human plays an essential role. For instance, pilots are important in all phases of an aircraft operation. The role of human may either be positive or negative by bringing an undesirable air event or correcting a negative action in a specific task situation. Time, skill, knowledge, technology are the main elements being in a positive or negative role in all situations, threatening the safety of the task. Thus, the concept of the human factor should be perceived in the relations between man-operator (pilot, air controller, aviation mechanic, etc.) and other areas appropriate for the operation of machines (aircraft) (Uchroński, 2020).

Ergonomic risk factors are related to the job aspects and may impose biomechanical stress on the worker, and those risk factors as synergistic elements may cause hazards (Iowa State University, 2021).

Ergonomic risk is underlined primary issue which is associated with the work environment. The main ergonomic risk factors resulting from job activities are listed below (UC San Diego, 2021).

- Awkward postures

- Bending

- Compression or contact stress

- Forceful exertions

- Insufficient rest breaks

- Lifting

- Lighting

- Noise

- Pushing, pulling

- Reaching

- Repetitive motions

- Static or sustained postures

- Temperature extremes

- Vibration

Baggage handling, for instance, involves similar tasks at all larger airports and is, characterized by heavy lifting, pushing, and pulling on the ground, and work in constrained and awkward postures, such as sitting, stooping, kneeling, and lying down (Bergsten, 2017). Stretching, reaching, and lifting may contribute to physical fatigue (ICAO, 2002). Ground operation workers need to kneel and do heavy handling while in a kneeling 
posture presents the greatest risk of back injuries (Riley, 2009). Ground handlers need to push and pull baggage cards, belt loaders, and aircraft steps while manually loading aircraft bulk holds. While insufficient rest breaks may increase the illnesses, short rest periods spent lying down will improve spinal cord nutrition (Riley, 2009).

Physical factors related to performing the required tasks, such as strength, height, reach, vision, and hearing, are significant and affect the individual performance. While designing the workplace, normal human physical differences must be considered. Individual tolerances for the differences in heat, pressure, light, noise, vibration, time of day, etc., need to be recognized (ICAO, 2002).

Working outdoors on a ramp, ground handling staff faces variations in temperatures, wind, noise, visibility, and lighting work surfaces. These factors affect physical well-being and create conditions for committing operational errors (ICAO, 2002).

Human error can be controlled by minimizing the probability of errors and reducing the consequences of any errors through cross-monitoring and crew cooperation. High levels of competence, proper checklists, procedures, manuals, maps, charts, and reducing noise, vibration, temperature extremes, and other stressful conditions may help control the probability of incidents/errors. Training programs that increase the cooperation and communication between crew members will also reduce the probability of errors. Equipment design to make errors reversible, and equipment that monitors or complements and supports human performance, also contribute to limiting errors and their consequences (ICAO, 2002)

Understanding and trying to predict human performance and limitations are fundamental issues of human factors. As in the other industries, in aviation management, considering of human factors has progressively developed and been refined, and this led to enhancing the safety in aviation operations today (ICAO, 2002). In addition to understanding human performance, physical job activities, workplace conditions, equipment characteristics, and workstation environmental conditions are very important (IOWA State University, 2021).

Ergonomic risk factors are explained as working conditions and/or operating processes that may contribute to the risk of developing work-related musculoskeletal disorders (MSDs). This includes damaged muscles, nerves, tendons, ligaments, joints, cartilage, or spinal disks (EMC, 2021). According to Middlesworth (2018), the major workplace ergonomic risk factors to consider are; forceful exertions, repetitive awkward postures, and repetition of high tasks.
Some ergonomic risk factors are certain and easy to identify however some are not as apparent or observable. So, employers should be ready to manage risk factors in the workplace via training and experience. Developing and implementing the ergonomics programs, staff may gain a proper working knowledge of the ergonomic risk factors related to workplaces (Iowa State University, 2021).

Ergonomic risk assessment is a proactive approach to occupational health and safety, which includes identifying the hazard, estimating the risk (likelihood and severity of harm), and making recommendations to control the risk where necessary (University of Cape Town, 2021).

Risk assessment is the process of risk analysis and risk evaluation. Risk analysis is the use of available information to identify hazardous tasks and to estimate the risk. Risk evaluation is the process based on the risk analysis but considering other factors, such as economic and social, in which judgments are made on the acceptability of the risk.

\section{Ergonomic Risk Factors in Ground Handling}

\section{Operations}

Ground handling staff face several challenges such as stress, tight turnaround times, safety standards shift, and night work in their daily work (Contego Aviation, 2018). Ground handlers are also exposed to de-icing chemicals, hydraulic fluids, jet fuel, and exhaust fumes which are risky for human health. Proper training and information on hazardous substances help to protect the staff and are crucial to minimizing potential risks.

On the other hand, baggage handlers using belt loaders are at risk of musculoskeletal diseases. Training and regular monitoring of workers are necessary to minimize these occupational problems (Contego Aviation, 2018).

In this section, significant ergonomic risk factors in ground handling operations are briefly explained.

Table 1. Taxonomy of Ergonomic Risk Factors

\begin{tabular}{ll}
\hline Main categories & Sub-categories \\
\hline \multirow{3}{*}{ Scheduling workload } & shift work \\
& staff shortage \\
& time pressure \\
& stress \\
out of control \\
loose concentration \\
vision/hearing loss \\
fatigue \\
musculoskeletal disorders \\
knowledge/skills \\
Physical strength & expectancies \\
& communication \\
\hline
\end{tabular}


A taxonomy of ergonomic risk factors for ground handling operation is developed under four main categories as; scheduling workload, mental conditions, physical strength, and qualifications. The supporting sub-categories of these main categories are shown in Table 1 (Luxhøj et al., 2001; Sari, 2015).

1. Scheduling workload: The physical and mental workload affects the health and performance of the ground handling personnel. The level of total workload is significantly affected by environmental and organizational factors as well as mental and physical factors.

The physical workload is also defined as the factors that are related to the biomechanical strains that occur in the body (Westgaard and Winkel, 1996). When any personnel works with a physical workload above their physiological capacity for a long time, it causes work accidents, faulty production, and health problems.

Mental workload is a concept formed by mental and perceptual activities such as calculation, decision making, remembering, and research (Delice,2016). Mental workload is the amount of mental work required to complete a task over a period of time. It appears when the requirements of a job and the skills, behaviors, and perceptions of the employees do not match each other (Emeç and Akkaya,2018).

Airline ground handling global standardization is essential for sustainability as emergencies and irregular shifts may increase work pressure, affecting individual health, corporate performance, and safety (Sun and Chiou, 2011).

Scheduling workload is a significant element as much as determining the shift work for the ground staff; if there is a shortage of staff under the time pressure operations, individuals have the potential to cause accidents and hurt themselves. Shift work is a source of occupational stress. Aviation is a 24-hour industry. This reality creates problems for many employees, such as ground crew, flight mechanics, and security personnel (Kushnir,1995).

Shortage of qualified staff is another important factor like time pressure and workload. There are several reasons for staff shortage, such as low pay and poor working conditions or unqualified personnel varying from country to country. Thus, a limited workforce has to take responsibility for the excessive workload (ICAO, 2002). The International Air Transport Association (IATA) stated that more than $50 \%$ of ground handling activities worldwide are handled by more than 1000 ramp handlers (iJET, 2021).

Time pressure affects the performance of an individual, which in turn can place the individual in a situation of committing an error (Kushnir,1995). The reason for the increase in demand for air transport is that it is the fastest transportation mode. To cover the demand, the industry faces constant time pressure and cost pressure. Faster turnaround times are also affecting the effectiveness of personnel and ground handling operations as well.

2. Mental conditions: The mental conditions of the personnel affect the performance depending on the reasons such as workload and time pressure. According to Luxhøj and Coit (2006), principal mental conditions were stress and anxiety, overconfidence, loss of situational awareness, and task saturation due to an event overload.

Stress is a diffuse and global negative experience accompanied by other negative emotions such as anxiety, frustration, dissatisfaction, and depression (Kushnir,1995). In the 1980s, stress-related illnesses accounted for more than 14\% (Raymond, 1988). Today, more and more people are becoming sick due to illnesses caused by stress (Harnois and Gabrie, 2000).

Out of control: The requirements of the working environment for ground handling are treated as stressors that cause stress. Intelligence, skill, knowledge, personality, and experience in stress-inducing situations are defined as the characteristics of personnel in developing coping strategies (Uchroński, 2020). The deterioration of the individual's functioning under stress increases the possibility of the wrong decision.

Loose concentration is caused by many reasons such as light, noise, other people, stress, fatigue, and more can be listed for ground handling staff. Lack of concentration or distraction is probably the biggest cause of traffic accidents and safety incidents and needs to be focused on (Techathammawong, 2016).

3. Physical strength of ground operations agents may be negatively affected by the aircraft movement on the ground. The noise may cause hearing from minor to permanent; the dust can cause eye irritation; fatigue may result in hurt, injury, and stress. Due to high work stress, shortage of staff, and other factors such as weather and excessive working hours, an individual can find himself in an awkward situation. The risk of fatigue exists in all activities of ground operations before the aircraft's arrival and during the aircraft on the ground (Sari, 2015).

Vision/hearing loss, known as occupational hearing loss, is one of the common work-related injuries in aviation. Noise exposure can be dangerous for pilots, cabin attendants, mechanics, and baggage handlers as they spend a lot of their time on the job in noisy environments. It is crucial to prevent people from longterm exposure for occupational health and safety (Smedje et al., 2011).

Human performance may adversely affect human fatigue, like sleep deprivation, circadian rhythm 
abnormalities, health-related tiredness, and taskinduced influences (Bendak and Rashid,2020). These adverse effects may lead to aircraft accidents.

Excessive working hours can cause musculoskeletal disorders. If the staff works in the same position for a long time, the person loses their body form and flexibility after a while, and recurrent pain occurs. It is very important to make work and workplace arrangements by using ergonomic analysis methods in order to prevent health problems caused by long working hours, increased stress, irregular working environments, and unsuitable environmental factors and to reduce total workloads (Adar and Delice, 2019).

4. Qualifications; every individual has different personality traits that are out of the control of top-level management. An individual's performance level could be affected by some personal factors such as background knowledge and trained skills, expectancies, communication abilities (Luxhøj et al., 2001).

Ground handling services include a wide range of tasks using several different types of equipment. Agents need to be sure that all the tasks are done properly in a coordinated way. Knowledge is power in the aviation industry; if the agent has the right job knowledge, it will help to minimize the risks, to do the job effectively, which results in satisfied customers.

A skill is an organized and coordinated pattern of psychomotor, social, linguistic and intellectual activity. Teaching is a skill in its own right, and the possession of skill in a particular activity does not necessarily indicate skill in teaching that activity to others. This is an important consideration in the selection of flight instructors, check pilots or anyone connected with a teaching activity. Skills, knowledge or attitudes gained in one situation can often be used in another. This is called positive learning transfer. Negative learning transfer occurs when previous learning interferes with new learning. It is important to identify the elements of training that can induce negative learning transfer since a return to earlier learned practices may occur in stressful situations (ICAO, 2002).

Expectancies: A frequently cited causal factor in aviation accidents is "expectancy"; i.e. individuals see what they want to or expect to see and hear what they want to or expect to hear. Auditors too are subject to the normal psychological process of expectancy, which is a form of conformity bias (ICAO, 2002 Doc 9806 AN/763)

Effective communication helps transfer essential information for operational safety. Transferring information may be verbal, written or via symbols and body gestures. The quality of communication is adversely affected by unclear or ambiguous messages, background noises, messages misinterpreted, impaired hearing, or non-native speakers (ICAO, 2002).
Miscommunication and misunderstanding among employees or between employee and supervisor may contribute to accidents/risk occurrence during operations.

Another significant factor observed is the training, which may directly affect the factors. Inadequate training for operation and the lack of comprehensive crew training had a vital effect on decision-making abilities (Luxhøj and Coit, 2006).

Training is a process aimed at developing specific skills, knowledge, or attitudes for a job or a task. On the other hand, lack of proper training may cause the sequence of unsafe acts. (ICAO, 2002).

Training is especially important for increasing situational awareness, and it is one of the fundamental parts of managing ergonomic risks. Ergonomic awareness training should consist of the following (the University of Cape Town, b, 2021):

- Identify the signs and symptoms of work-related musculoskeletal disorders (WMSDs) and the importance of early reporting.

- Recognize workplace risk factors for WMSDs and understand general methods for controlling them.

- Recognize the employee's role in the process; employees know their jobs better than anyone else knows and are often the source of ideas to improve them.

- There should be open interaction between trainers and trainees.

- Employees need to know the procedure for reporting ergonomic risk factors and musculoskeletal disorders.

The best ergonomic solutions are based on the expertise of the workers. They know their bodies and can best identify what activities take the most tolls and effort.

In this study, ergonomic risk factors in ground handling operations are developed by reviewing the literature (Chang and Wang, 2010; Toriizuka,2001, Rankin et al.,2000; Reason, 2000; Reason, 1997; Fogarty, 2004) and taking experts opinions on human performance.

\section{Conclusion}

As stated by most of the studies, the human factor is still the weakest part of the aviation system, especially in accidents and incidents, so it is fundamental to carry out permanent preventive activities related to human factor for improving flight safety, As a result of ergonomic risk factors faced by ground handling personnel, which is the main subject of this study, it is essential to determine risk factors, complete the necessary training and take 
precautions in order to prevent both loss of life and property and accidents (Uchroński, 2020).

In this study, ergonomic risk factors are developed by considering the related literature and taking experts' opinions.

The taxonomy developed in this study may provide to the manager making accurate and timely decisions. Especially, the managing ergonomic factors, as a decision-making problem, always exists at the top manager's agenda. Ground handling operational managers need decision-making processes to help them understand interactions in today's multivariate business environment.

In this study, to reach an effective and applicable taxonomy example for ground handling operations in Turkey, online interviews are conducted with one ramp supervisor, three academic staff, and two graduate program students via Zoom. In this taxonomy, all possible risk factors related to the ground handling operation are classified into four main groups as "scheduling workload, mental conditions. physical strength and qualifications". All these main groups are divided into sub-factors. Those are "shift work, staff shortage, time pressure, stress, out of control, lose concentration, vision/hearing loss, fatigue, musculoskeletal disorders, knowledge/skills, expectancies, communication", which are also critical to prevent error-based business interruptions, faultinduced accidents, and crashes resulting high economic losses and fatal.

This study has limitations on ergonomic factors to be examined. However, risk factors affecting corporate performance depend on various fields such as managerial decision skills, equipment, and technology, human resources, investments, communication with partners, etc. For this reason, in the future study, not only ergonomic risk factors but also organizational, human resources, and sustainability risk factors can be studied. With the help of risk analysis and multi-criteria decision

\section{Abbreviations}

\begin{tabular}{lll}
\hline CPM & $:$ & Corporate Performance Management \\
HRM & $:$ & Human Resource Management \\
MSD & $:$ & Musculoskeletal Disorders \\
IATA & $:$ & International Air Transport Association \\
WMSD & $:$ & Work-Related Musculoskeletal Disorders
\end{tabular}

\section{CRediT Author Statement}

Ebru Yazgan: Conceptualization, Writing- Original draft preparation, Visualization, Investigation, Supervision, Writing - Review \& Editing, Project administration Vildan Durmaz: Conceptualization, Writing- Original draft preparation, Visualization, Investigation, Supervision, Writing - Review \& Editing, Project administration Ayşe Küçük Yılmaz: Writing - Review \& Editing.

\section{References}

Adar, T. and Delice, E.K., 2020, Comparison of the total workload of local public transportation drivers with a new approach according to physical and mental workload criteria. Pamukkale University Journal of Engineering Sciences, 26(1), 254-267.

Asadi, H., Mott, J.H., Yu, D., 2019, Risk factors for musculoskeletal injuries among airport customer service employees, Proceedings of the Human Factors and Ergonomics Society 2019 Annual Meeting, pp.1964-1968

Bastola, D.P., 2017, Models and Measurements of Organizational Performance with Particular Reference to The Aviation Industry, international Journal of Current Research Vol. 9, Issue, 09, September, pp.58393-58402, ISSN: 0975-833X

Bendak, S. and Rashid, H.S.J., 2020, Fatigue in aviation: A systematic review of the literature, International Journal of Industrial Ergonomics, Volume 76, 102928.

Bergsten, E. L., 2017, Working conditions and musculoskeletal disorders in flight baggage handling. Digital Comprehensive Summaries of Uppsala Dissertations from the Faculty of Medicine 1321. 59 pp. Uppsala: Acta Universitatis Upsaliensis. ISBN 978-91-554-9868-9

Can, G.F. and Delice, E.K., 2017, A New Equation for Determining Physical Workload: A Case Study in A Box Letter Manufacturing Process International Symposium for Production Research, Vienna.

Chang, Y.H. and Wang, Y.C., 2010, "Significant human risk factors in aircraft maintenance technicians", Safety Science, 48 (1), pp. 54-62.

Čokorilo, O., Dell'Acqua, G., 2013, Aviation Hazards Identification Using Safety Management System (SMS) Techniques, May, Conference: 16th International conference on transport science ICTS 2013, Available at: Portorož, Slovenia http://epa.edu.pe/pdf/Cokorilo_DellAcqua.pdf

Contego Aviation, 2018, The health and safety hazards faced by airport ground handling staff, Contego 
Aviation Solutions, Available https://www.contegoaviation.co.uk/healthsafety-hazards-faced-airport-ground-handlingstaff / (Accessed in 14.06.2021).

Delice, E.K. (2016). Acil Servis Hekimlerinin Nasa-Rtlx Yöntemi İle Zihinsel İş Yüklerinin Değelendirilmesi: Bir Uygulama Çalışması. Atatürk Üniversitesi İktisadi ve İdari Bilimler Dergisi, Cilt: 30 Sayı: 3.645662.

Duignan, C.A., Fallon, E. F., 2005, Best Manual Handling Practices at Dublin Airport Final Report, Health and Safety Authority, Available at: https://www.hsa.ie/eng/Workplace_Health/Ma nual_Handling/Manual_Handling_Research_Rep orts/Manual_Handling_Dublin_Airport.pdf, ISBN 1-84496-024-2

Dupin, S., Thiebaut, T., Turcot, N., 2015, Ground Handling and Flight Safety Basics, Best Practices and Awareness-Raising, Technical Guide, Civil Aviation Technical Center Capacity, Environment, Master plans department, DGAC, STAC

Ek, A., Akselsson, R., 2007, Aviation on the Ground: Safety Culturein a Ground Handling Company, The International Journal of Aviation Psychology,17(1), 59-76

EMC Insurance Companies, 2021 Ergonomic Risk Factors, Tech Sheets, Loss Control, Business Life Reinsrunce, Available at: https://www.emcins.com/losscontrol/techsheet. aspx?techsheetid=566 (Accessed May 31, 2021)

Emeç, Ş. and Akkaya, G., 2018, Sağlık Sektöründe Zihinsel İş Yükü Değerlendirmesi Ve Bir Uygulama. Ergonomi 1(3), 156 - 162.

European Commission (EC)., 2021, Air-Groundhandling. Mobility and Transport, Available at: https://ec.europa.eu/transport/modes/air/airpo rts/ground_handling_market_en, (Accessed 21.03.2021).

FAA Federal Aviation Administration, 2007, Operator's Manual Human Factors in Airport Operations, HFMAO-07-01, Available at: https://www.faa.gov/about/initiatives/maintena nce_hf/library/documents/media/support_docu mentation/opsman_ramp_final.pdf

FAA ATA Specification 113- Chapter 7, Ergonomics, Maintenance Human Factors Program Guidelines, Available

at: https://www.faa.gov/about/initiatives/maintena nce_hf/library/documents/media/mx_faa_(for merly_hfskyway)/ata_specification_113_maintena nce_human_factors_program_guidelines/chapte r7.pdf
Fogarty, G. J., 2004, "The role of organizational and individual variables in aircraft maintenance performance", International Journal of Applied Aviation Studies, 4(1), 73-90.

Guest, D.E., Michie, J., Conway, N. and Sheehan, M., 2003, Human Resource Management and Corporate Performance in the UK, British Journal of Industrial Relations, 41:2 June, 0007-1080 pp. 291-314

Harnois, G., Gabrie, P., 2000, Mental health and work: Impact, issues and good practices, World Health Organization, Geneva: WHO/MSD/MPS/00.2 ISBN 924159037 8, ISSN 1726-1155

ICAO, 2002, Doc 9806 AN/763, Human Factors Guidelines for Safety Audits Manual, Chapter 6, Human Factors in Aircraft Maintenance, Human Factors Guidelines for Safety Audits Manual, First Edition, International Civil Aviation Organization

iJET, The Top Challenges Facing Airport Ramp Operations, Available at: https://ijet.aero/ijetblog/challenges-ramp-operations, (Accessed: April $25,2021)$.

Iowa State University, 2021, Risk Factors, Environmental Health and Safety, Available at: https://www.ehs.iastate.edu/services/occupatio nal/ergonomics/risk-factors.

Kansoy, S.U., Bakanoğlu, K., 2021, The Importance of Human Factors in Aviation Companies, International Journal of Arts and Social Science, Volume 4, Issue 2, Available at: www.ijassjournal.com, ISSN: 2581-7922, (MarchApril.)

Kushnir, J., 1995, Stress in ground support personnel, En J. Ribak, R.J. Rayman y P. Froom (Eds.), Occupational health in aviation: Maintenance and support personnel (pp. 51-72), San Diego, California: Academic Press.

Luxhøj, J.T., Choopavang, A., Arendt, D.N., 2001, Risk Assessment of Organizational Factors in Aviation Systems, Air Traffic Control Quarterly, Vol. 9(3) 135174 CCC 1064-3818/95/030163-20

Luxhøj, J.T., 2002, Risk analysis of human performance in aviation maintenance, 16th Human Factors in Aviation Maintenance Symposium, April 2-4, Available at: https://www.faa.gov/about/initiatives/maintena nce_hf/library/documents/media/mx_faa_(for merly_hfskyway)/16th_symposium/risk_analysis _of_human_performance_in_aviation_maintena nce.pdf

Luxhøj, J.T., Coit, D.W., 2006, Modeling Low Probability/High Consequence Events: An Aviation Safety Risk Model, RAMS '06, Annual Reliability and 
Maintainability Symposium, 2006, IEEE Xplore Newport Beach, CA, USA, Available at: https://citeseerx.ist.psu.edu/viewdoc/download? doi=10.1.1.121.3175\&rep=rep1\&type=pdf $\quad$ (DOI: 10.1109/RAMS.2006.1677377)

Middlesworth, M., 2018, The Art and Science of Injury Prevention, ErgoPlus, 2021, Available at: https://www.ergo-plus.com/the-art-andscience-of-injury-prevention/, (Accessed May 31, 2021)

Raymond, C. A., 1988, Mental stress: "Occupational injury" of the 1980's that even pilots can't rise above.J.A.M.A. 21, 3097-3098.

Rankin, W., Hibit, R., Allen, J. and Sargent, R., 2000, "Development and evaluation of the Maintenance Error Decision Aid (MEDA) process", International Journal of Industrial Ergonomics, Vol. 26, pp. 261-76.

Reason J., 2000, "Human error: models and management", British Medical Journal, 320 (7237), pp. 768-770.

Reason J., 1997, Managing the risks of organizational accidents, Aldershot: Ashgate, United Kingdom.

Riley, D., 2009, Reducing the risks associated with the manual handling of air passenger baggage for narrow bodied aircraft, RR674 Research Report, Health and Safety Laboratory, HSE Books - Health and Safety Executive.

Sari, M., Arubusman, D.A., Abbas, S., 2015, Airport Ramp Risk Analysis at Halim Perdanakusuma, Jurnal Manajemen Transportasi \& Logistik, Vol2, No 3, Nov. ISSN 2355-4721

Seeley, P., 2009, Safety Matters: Ergonomics Make Sense for Your Health and Your Bottom Line, Aviation Pros, Available https://www.aviationpros.com/aoa/aircraftrescue-firefighting-arff/arfftraining/article/10374507/ergonomics

Smedje G, Lundén M, Gärtner L, Lundgren $H$, and Lindgren T., 2011, Hearing status among aircraft maintenance personnel in a commercial airline company, Noise Health, [serial online], 2011, 13:364$70 . \quad$ Available at: https://www.noiseandhealth.org/text.asp?2011/1 3/54/364/85509, (Accessed Sep 5 2021)

Sun, K.S. and Chiou, H., 2011, Aviation ground crews: Occupational stresses and work performance, frican Journal of Business Management Vol. 5(7), pp. 2865-2873, 4 April, 2011, Available at http://www.academicjournals.org/AJBM, DOI: 10.5897/AJBM10.1333 ISSN 1993-8233, (Accessed Aug 31 2021)
Techathammawong, T., 2016, AVT1305 Airport Ramp Operations, Airport Management Program International College of Mekong Region Chiang Rai Rajabhat University, Available at: http://icmr.cru.ac.th/.

Toriizuka, T., 2001, "Application of performance shaping factor (PSF) for work improvement in industrial plant maintenance tasks", International Journal of Industrial Ergonomics, 28, pp. 225-236.

UC San Diego, 2021, Ergonomics: Risk Factors, Ergonomics, Occupational, Safety, Regents of the University of California.

Uchroński, P., 2020, Analysis of the Operation of the Ground Handling Agent in the Aspect of Safety, Journal of KONBiN, Volume 50, Issue 1, pp.319-339, DOI 10.2478/jok-2020-0019 Available at: https://www.researchgate.net/publication/34166 0234_Analysis_of_the_Operation_of_the_Groun d_Handling_Agent_in_the_Aspect_of_Safety, (Accessed Jun 15 2021)

University of Cape Town (a), 2021, Module: introduction to Ergonomics, Ergonomic Risk Factors, Faculty of Health Sciences, School of Publish Health and Family Medicine, Post Graduate Diploma in Occupational and Environmental Health, 2021.

University of Cape Town (b), 2021, Module: introduction to Ergonomics, The Process of Ergonomics Workplase Risk Assessment, Faculty of Health Sciences, School of Publish Health and Family Medicine, Post Graduate Diploma in Occuoational and Environmental Health, 2021.

Westgaard, R.H., Winkel, J., 1996, Guidelines for occupational musculoskeletal load as a basis for intervention: a critical review, Applied Ergonomics, 27.

Wigmore, I., 2015, Corporate performance WhatIs, Available at: https://whatis.techtarget.com/definition/corpor ate-performance

Yazgan, E., 2018, Development taxonomy of human risk factors for corporate sustainability in aviation sector, Aircraft Engineering and Aerospace Technology, 90(6):1012-1022 